\title{
Networking of Educational Organizations of General and Higher Education: Infrastructure Project
}

\author{
Sergey Georgievich Vorovshchikov ${ }^{1 *}$, Olga Andreyevna Lyubchenko ${ }^{1}$, Aishat \\ Shahmadovna Shakhmanova ${ }^{1}$, Andrey Alexandrovich Marinyuk ${ }^{1}$, and Lhaamtseren Bold ${ }^{2}$ \\ ${ }^{1}$ Moscow City University, Moscow, Russia \\ ${ }^{2}$ Institute of education of Mongolia under the Ministry of education, culture, science and sports, \\ Ulaanbaatar, Mongolia
}

\begin{abstract}
The article deals with organizational details and results of the infrastructural project that has been implemented over 15 years in several Moscow schools with consulting support of a pedagogical university. The goal of the project: through the interaction of schools and the university, develop and test a comprehensive system of didactic and methodological support for the development of research culture in schoolchildren as a metasubject result. Such support has been designed as a complex intraschool didactic and methodological system that includes the priority values and goals of meta-subject education, the determination of the activity-based component of meta-subject education content, the projects of meta-subject courses, methodological recommendations on designing meta-subject lessons and organizing students' research. This system of didactic and methodological support requires managerial assistance that ensures coordination and consistency in the work of additional education pedagogues, teachers, university teachers who consult student research.
\end{abstract}

\section{Introduction}

The tasks that a modern school faces are innovative and require systemic solutions for their efficient implementation [1-10]. One of such difficult innovative tasks is set in the Russian educational standard of general education: students must achieve meta-subject education results. However, after a decade of implementing the standard, schools still do not have specific answers to key questions: what is the content of meta-subject results; what should be the didactic and methodological support for the students to achieve these results?

One must admit that mainstream schools lack the necessary level of scientific and methodological potential to solve complex innovative tasks. In view of this, there is an obvious need for modern formats of cooperation between school employees who have to solve systemic problems and university teachers who are willing to help schools as much as needed.

\footnotetext{
*Corresponding author: vorovshikovsg@mpgu.ru
} 
Network cooperation is an efficient form of interaction between schools, pedagogical universities, and other social partners as it is beneficial for all parties:

- school managers and teachers get swift and relevant expert and scientificmethodological consulting assistance in solving complex innovative problems in education;

- faculty members of a pedagogical university are methodologically involved in solving actual pressing didactical and methodological problems of schools.

Educational and research partnership as any productive network cooperation, on the one hand, is beneficial for all parties and, on the other hand, imposes certain obligations for the integration of research, program and informational, and other resources.

Fifteen years ago, the implementation of the infrastructural project was begun that united several Moscow schools with consulting support of a pedagogical university [11]. The goal of the project: through the interaction of schools, methodological services of the capital's education district and the pedagogical university, design, theoretically justify and test a comprehensive system of didactic and methodological support for meta-subject education. The purpose of this article is both to reveal the features of consulting support methods of this project that united educational organizations from different departments and to provide the results of an aspect of this project - the comprehensive package of didactic and methodological support for developing the students' research culture.

\section{Methods}

The main techniques of consulting support for network cooperation between a group of schools and the pedagogical university were project consulting and process consulting. Within the framework of project consulting, a consultant or a consulting group develop projects for solving the problem that caused the need to create an educational and research cluster of network interaction between the pedagogical university and schools. Those can be projects of managerial, psychological, didactic and methodological, and other documents that are discussed, corrected, and put into practice by school managers and teachers. Consultants create projects of solutions and school managers and teachers act as experts. The format of process consulting entails joint exploratory, research, project work of consultants, managers, and pedagogues. This method is implemented according to the comprehensive management cycle: from identifying the issues in the education process, searching, choosing, and creating the most efficient solutions to analyzing the process and results of implementing the defined solutions $[12,13]$. In this case, school employees act as project designers and consultants are experts in projects of managerial and didactic-methodological materials.

The development and testing of the intraschool system for the development of research culture as a content component of meta-subject education was carried out in three stages: project $(2003$ - 2005), constructive-correctional (2005 - 2009) and analytical-generalizing (2009-2018) [11]. The development trend of research skills was set according to two levels. Basic level: the student had some integrative research skills and the teacher helped the student to conduct research. Advanced level: the student had all the integrative research skills and conducted the research independently. The indicators of the trend of research skill formation included the increase in the share of independent research, the degree of awareness in the realization of research skills, and the willingness to implement the interconnected set of integrated skills of correct student research procedure. We used three evaluative procedures to monitor the trend of the research skills: research evaluation by the supervisor and the jury of the school conference; marks set as part of the course "Introduction to Project and Research Activities"; student self-assessment. The results indicate that the comprehensive use of the intraschool system of meta-subject education foster a more harmonious development of research culture. 


\section{Results}

As results of network interaction between the school and the pedagogical university, we provide a list of didactic and methodological documents created and tested within the framework of a long-term social partnership for solving the pressing issue of research culture development in students:

1. At the level of general education: classification of general educational skills as a result and resource of research activity; the academic and methodological complex of the metasubject course "Introduction to Project and Research Activities", including the curriculum, the study guide for high school students [14] and teaching aids for teachers, and a monitoring workbook; the technology for designing meta-subject lesson plans; projects of didacticmethodological and managerial documents on organizing students' project and research activities that have guiding, advisory, and regulatory nature; a set of cases aimed at exploring the teachers' methodological proficiency; an organizational system model and a set of monitoring tools for studying general educational skills as a component of students' research culture; management technology for the analysis of preparing and conducting a meta-subject lesson, etc. [11].

Therefore, the didactic and methodological support of an organization and students' research activities includes both methodological and didactic strategic and tactical documents of regulatory and advisory nature. This set of documents should be annually discussed, corrected, and approved by the Pedagogical Council and Students' Scientific Society, and should be provided to all participants: students and their parents, teachers, and additional education pedagogues acting as academic consultants.

2. At the level of additional pedagogical education: an academic and methodical complex of the further education program for school teachers dedicated to the development of research culture in schoolchildren, including multimedia presentations, a set of case studies, and monitoring tools [15-17].

3. At the level of higher pedagogical education: didactic and methodological support of the Master's pedagogical program "Meta-subject education" which entails professional training in the development of research culture in schoolchildren [18-19].

\section{Discussion}

One must admit that there is no comprehensive theory of meta-subject education in Russian pedagogy. Currently, Russian researchers' few publications dedicated to the students' achievement of meta-subject educational results are only starting to emerge abroad. In fairness, it is worth noting that only two Russian pedagogical research schools lead by Yu.V. Gromyko [11] and A.V. Khutorskoy [14] conducted comprehensive theoretical and practical research of meta-subjectivity for 15 years. While Yu.V. Gromyko proceeded primarily from psychological studies, A.V. Khutorskoy used philosophical ideas of Russian cosmism as the methodological foundation for interpreting meta-subjectivity.

According to A.V. Khutorskoy, the content of meta-subject education includes fundamental educational objects; general cultural knowledge on fundamental paradigms; naturally, general educational skills; meta-subject competences [20].

Such an interpretation of meta-subject content is based on the philosophical paradigm of education that views the student as the subject with a physical body, intellect, emotions, and certain spiritual and moral values.

For $\mathrm{Yu}$.V. Gromyko, the content of meta-subject education is a certain integration of the following components:

1) Activity-based component of the education content. This refers to not only skills but also knowledge if the student has mastered the practical application of the knowledge. 
2) Activity-based reinterpreted subject content of education allows one to reinterpret the narrow specialization of subject material.

3) Priority development of basic abilities that include the ability to imagine, think, selfmanage one's vital activities is an important characteristic of meta-subject integration [21].

Therefore, researchers do not primitively limit the power of the content of meta-subject education by a list of universal actions that is present in the Russian standard of general education.

Researchers agree that the implementation of the meta-subject approach fosters a comprehensive worldview and the cognition of the real world as a system of fundamental educational objects. Members of both research schools confirm the interpretation of the priority role of the meta-subject course in the didactic system of meta-subject education.

Thus, A.V. Khutorskoy defines meta-subject as a subject dedicated to comprehending single education objects or a comprehensive system of such objects rather than to studying universal learning activities. Thorough examination entails broad coverage of related problems, studying of corresponding competences [21]. According to A.V. Khutorskoy, the main element of studying a meta-subject is the student's constant state of self-actualization: the student obtains everything themselves through heuristic activity rather than receives everything in its final form [21].

Yu.V. Gromyko is consistent in his beliefs: for the researcher, meta-subject is, first of all, an activity-based interpretation of learning material that is based on the reflection of basic gnoseological elements: "problem", "task", and "knowledge" [20].

A.V. Khutorskoy, following the Postulate of Human Congruity, defined the pillar of a meta-subject lesson, "Any question or topic is first stated by the students at their level of understanding. The children's answers and opinions are discussed, compared, and commented. The teacher provides no assessments such as "right-wrong". After the students created their own educational product - a drawing, version, table, etc., the teacher introduces them to the cultural and historical versions of the solution to the same problem that the students have been solving. The teacher provides quotes from the source material and discusses them with students, compares the definitions given by students with definitions created by scholars, provided in dictionaries and encyclopedias. There is a comparison of the material studied with the content personally created by the student. As a result, each student says that they did best, how the result was achieved, what they liked, and remembered the most. This is called the reflective stage. The goal is for each student to realize their results, difficulties, and methods of their own activity. On the basis of the reflective stage, selfassessment and evaluation of educational results take place" [21].

Researchers believe that specific content of general education requires adequate educational technologies to complete it, for example, the organization of students' project and research activities. A.V. Khutorskoy's research school studies the organization of student research primarily in the mode of remote conferences based on the heuristic approach to education.

We are convinced that meta-subject education as a complex sociocultural system involves the development of multi-level academic and methodological support not only in the form of individual methodologies for the development of students' research abilities or individual meta-subjects but also detailed, thoroughly justified designing of curricula for various levels of general education. Due to the high innovative coefficient of the development of research culture as a component of the meta-subject education content, the school has to abandon the traditional methodological work, that, as you know, comes down only to the search and generalization of advanced pedagogical experience. It is the scientific and methodological work that should efficiently solve innovative problems of education through the innovative academic and methodological solutions created by teachers with appropriate consulting support. As a result of such work, on the one hand, efficient didactic and methodological 
solutions are created, on the other hand, the willingness of school employees to implement these solutions is gradually increasing.

\section{Conclusion}

Therefore, the development of research culture in schoolchildren as a meta-subject result requires network interaction of general and higher pedagogical educational institutions. In the interaction with the school, the pedagogical university must act as a systemic catalyst that integrates the resources of all social partners willing to assist the school in developing the students' research culture. This is obvious since the most competent social partner for a school is a pedagogical university, the faculty members of which have the necessary level of psychological-pedagogical and didactic-methodological expertise and possess the required consulting technologies.

The efficiency of network interaction between social partners is achieved by combining ideological, reputational, program, personnel, research-methodological and materialfinancial resources. It is feasible to carry out resource integration based on a contract that defines the goals of joint activities, rights and obligations of the parties, and the interaction procedure.

Mutually beneficial network interaction can be an efficient form of interaction between the school, the pedagogical university, and other social partners:

- school employees get the necessary consulting research and methodological support in psychological and pedagogical assistance of achieving meta-subject results, can participate as clients, students, or academic training co-managers when there are school-based practiceoriented further education programs on the challenges of meta-subject education, dual education of students following the corresponding Bachelor and Master programs at the pedagogical university.

- faculty members of a pedagogical university are methodologically involved in solving actual pressing didactical and methodological problems in the education process of modern schools, can participate in the implementation of the corresponding further education programs for teachers, can open certified remote school-based campuses of internship and academic practices.

The strategic goal of this infrastructural project is to develop and implement the didactic and methodological support for research culture development in schoolchildren through network interaction between the pedagogical university, the school, municipal methodological services, and children's additional education organizations.

It should be noted that the development and implementation of academic and methodological support for the development of research culture, in turn, involves research into the creation of the necessary managerial support in the future. This support may include both an all-encompassing management technology for designing and implementing an intraschool system for helping students to learn research culture, as well as private management resources, for example, monitoring tools for studying the proficiency in priority general educational skills, etc. Management instrumentarium should coordinate the activities of teachers at the same level of general education, additional education pedagogues, university teachers consulting educational research. Moreover, it is management that should initiate the design, implementation, and constant updating of academic and methodological support for meta-subject education in general and research culture in particular. 


\section{References}

1. A.G. Majuga, S.G. Vorovshchikov, E.V. Golovneva, R.M. Salimova, Perspectives of science and education 6(42), 20-30 (2019)

2. A.I. Savenkov, A.S. Lvova., O.A Lyubchenko, L.E. Osipenko, Bulletin of the Moscow city pedagogical university 2(36), 54-61 (2016)

3. A.P. Sukhodimtseva, N.I. Vorozheikina, Yu.B. Eremina, Smart Innovation, Systems and Technologies 138, 501-510 (2020)

4. A.V. Kondaurova, N.N. Surtaeva, V.V. Afanasev, O.A. Ivanova, R.G. Rezakov, Espacios 39(46), 19-26 (2018)

5. J.A. Skurikhina, R.A. Valeeva, N.P. Khodakova, E.V. Maystrovich, Eurasia Journal of Mathematics, Science and Technology Education 14(12), (2018)

6. M.G. Sergeeva, I.Yu. Sinelnikov, A.P. Sukhodimtseva, The European Proceedings of Social \&Behavioural Sciences (EpSBS) 62, 531-539 (2017)

7. O.Yu. Zaslavskaya, A.A. Zaslavskiy, V.E. Bolnokin, O.Ja. Kravets, International Journal on Information Technologies and Security 10, 93-102 (2018)

8. S. Vorovshchikov, E. Artamonova, Ch. Speshneva, F. Sabiyeva, R. Urazalieva, Espacios 40(12), 252019.

9. T.V. Koval, A.Yu. Lazebnikova, The European Proceedings of Social \&Behavioural Sciences, 28 379-387, 2017.

10. T.V. Masharova, N.I. Marinina, Education and science 7(126), 181-191 (2015)

11. Yu.V. Gromyko, Mysledeyatelnostnaya pedagogica (Minsk, 2000)

12. K.A. Abulkhanova, Psychological Journal 35(2), 5-18 (2014)

13. E.A. Gevurkova, I.Yu. Sinelnikov, A.P. Sukhodimtseva, Integrative Strategies For Teaching And Learning As A Renewal Of School Education, International Conference "Education Environment for the Information Age", Moscow, Russia, (2017)

14. A.V. Khutorskoy, Metasubject approach in training (Eydos publishing house, Moscow, 2012)

15. V.V. Afanasyev, O.A. Ivanova, R.G. Rezakov, I.V. Afanasyev, S.M. Kunitsyna, International journal of civil engineering and technology 10(2), 1612-1637 (2019)

16. M.N. Dudin, V.V. Afanasev, I.V. Afanasieva, R.G. Rezakov, Amazonia Investiga 8(21), 674-687 (2019)

17. G. Golub, E. Kogan, I. Fishman, Standards and Monitoring in Education 4(6), 50-60 (2016)

18. E. Caner, I. Acun, G.Demirhan, Journal of Social Studies Education Research 6(1), 190207 (2015)

19. G.N. Germanov, S.I. ilimonova, I.A. Sabirova, Scientific notes of Lesgaft National State University of Physical Education, Sport and Health 2, 43-51 (2015)

20. O. Chigisheva, E. Soltovets, A. Bondarenko, Xliguae 4, 138-153 (2017)

21. L.Ya. Dofman, Psychological Journal 37(1), 26-34 (2016) 